\title{
EL POSTPENTECOSTALISMO. LA CONCEPCIÓN DE LOS MIGRANTES PERUANOS Y BOLIVIANOS EVANGÉLICOS (QUECHUAS Y AYMARAS) SOBRE EL PENTECOSTALISMO CHILENO**
}

\author{
THE POST-PENTECOSTALISM. THE CONCEPTION OF PERUVIAN \\ AND BOLIVIAN MIGRANTS (QUECHUAS AND AYMARAS) ON CHILEAN \\ PENTECOSTALISM
}

Miguel Ángel Mansilla**, Wilson Muñoz ${ }^{* * *}$ y Carlos Piñones Rivera****

El objetivo de este artículo es analizar la visión que manifiestan los creyentes migrantes indígenas evangélicos acerca del pentecostalismo chileno, explorando la relación que establecen entre esta forma de pentecostalismo y la que profesaban en sus países de origen. Esta visión se complementa con la visión nostálgica que evidencia un sector del pentecostalismo y una generación de creyentes críticos y reflexivos respecto del movimiento religioso. Las dos visiones desencantadas corroboran la visión nostálgica y crítica de los migrantes.

Palabras claves: Pentecostalismo, postpentecostalismo, indígenas, migración, norte de Chile.

The objective of this article is to analyze the indigenous evangelical migrants'beliefs about Chilean Pentecostalism, exploring the relationship between this form of Pentecostalism and that which they professed in their countries of origin. This vision is complemented by the nostalgic vision that evidences a sector of Pentecostalism and a generation of critical and reflective believers about the religious movement. The two disenchanted visions corroborate the nostalgic and critical view of the migrants

Key words: Pentecostalism, post-Pentecostalism, indigenous, migration, northern Chile.

\section{Introducción}

La crisis es el emblema de la sociedad actual, pero cual Mida todo lo palpado entra en crisis. Cada época tiene sus crisis: una de ellas fue en la década de 1960, pero en ese contexto aparece la antropología (Willems, 1967) y la sociología (D'Epinay, 1968) que se interesaron en investigar al pentecostalismo chileno, siendo uno de los más importantes en ese entonces junto a Brasil, creando los conceptos de huelga social y refugio de las masas, que hasta hoy son los conceptos más relevantes. Tanto la sociología como la antropología de las religiones se destacaron por dos motivos: a) desvelar un objeto de estudio ignorado hasta entonces; de ahí el pentecostalismo se tornó relevante antropológica y sociológicamente; b) la virtud de ambos autores no estuvo solo en correr el velo de un objeto, sino, lo más importante, construir conceptos que permitieran analizar un fenómeno religioso que estaba ahí, pero ahora se tornó significativo. ¿Por qué sucedió eso?, porque "con distintos conceptos se construyen distintos mundos. Solamente es posible observar a través de conceptos, nada es comprendido fuera de él" (Luhmann1996:12). No significa que el concepto se eleve como demiurgo frente a la investigación, sino "que todo acto de investigación es simultáneamente empírico y teórico" (Bourdieu y Wacquant, 2008:63).

En nuestra investigación hemos observado y escuchado que los entrevistados perciben una crisis del pentecostalismo en la zona de estudio. Pero como investigadores también hemos advertido una crisis en los estudios antropológicos del pentecostalismo y que no permiten comprender y aprehender dicho fenómeno. Pero no se trata de una crisis epistemológica, porque en última instancia como nunca se valora la voz del sujeto (subalterno, la otredad o popular). Tampoco se trata de una crisis de campo de estudio, porque existe un notable trabajo etnográfico. Se trata más bien de una crisis teórica, que parte por la insuficiencia analítica de los conceptos utilizados. Obviamente

\footnotetext{
* Resultado Proyecto de Investigación Iniciación No 11140698.

** Universidad Arturo Prat, Iquique, Chile. Correo: mansilla.miguel@gmail.com

*** Universidad de Tarapacá, Arica, Chile. Correo electrónico: wilsonsocio@gmail.com

*****Universidad Arturo Prat, Iquique, Chile. Correo electrónico: carlospinonesrivera@ gmail.com
} 
esto no es una crisis nueva, sino que sucede de cuando en cuando, y es algo que Clifford Geertz destacó diciendo que "el estudio antropológico de la religión está en un estado de estancamiento general" (Geertz, 2005: 87). Por tanto urge salir de tal estado y para ello hay que recurrir a los teóricos, no para seguir ocupando sus conceptos, sino para seguir sus sugerencias. Por ejemplo, Lhumann destaca que para avanzar hacia una mayor riqueza conceptual hay que ser multidisciplinar, recurriendo desde la teología hasta la biología (Lhumann, 1996:13). En el mismo plano Geertz señala que la perennidad de la antropología de las religiones aumentará en la medida que se recurra a otras disciplinas como la historia o la literatura (Geertz, 2005; 87).

No se trata de una tarea fácil porque siempre están el miedo al reduccionismo y de la especulación, ya sea por el exceso del dato o de la generalización. Para evitar esos extremos, Víctor Turner destaca que para analizar la estructura y propiedades de los símbolos rituales se puede lograr por medio de tres clases de datos: a) las formas externas y característica observables; b) la interpretación ofrecida por los especialistas religiosos y por los simples fieles y c) el contexto significativo elaborado por el antropólogo (Turner, 1980: 22). Esto es, que la responsabilidad y la centralidad recaen en el investigador para observar, dialogar y construir conocimiento mediante el análisis de la información y "al observar o describir los hechos con pretensiones científicas, deben construirse conceptos. Solo es posible observar lo que se ha construido con esos conceptos y por lo tanto con distintos conceptos se construyen distintos mundos" (Luhmann, 1996:13). $\mathrm{Y}$ ese ha sido nuestro norte.

Entendiendo que no se puede construir conceptos obviando el trabajo de campo o bien considerarlo como un mero dato, incluso como un obstáculo, sino a partir de él. Así nos esforzamos en "evitar la audacia del sin rigor y el rigor sin audacia" (Bourdieu y Wacquant, 2008: 60). Este artículo se enmarca en un proyecto más amplio en el que nos propusimos como objetivo desarrollar un esquema de propuesta y análisis teórico-conceptual respecto de los migrante evangélicos (peruanos y bolivianos de origen quechua y aymara) en relación con sus vínculos comunitarios. Por tanto el objetivo de este artículo es analizar la visión que transmiten los creyentes migrantes indígenas evangélicos acerca del pentecostalismo chileno, explorando la relación que establecen entre esta forma de pentecostalismo y la que profesaban en sus países de origen. De igual modo se trata de compararlo con las realidades pentecostales observadas de los templos de origen de los migrantes. Para alcanzar nuestro objetivo mayor, hemos utilizado una metodología cualitativa. Realizamos 40 entrevistas a hombres y mujeres migrantes evangélicos de origen quechua y aymara que residen en las ciudades de Arica e Iquique. También realizamos cinco entrevistas a líderes de iglesias evangélicas de las ciudades de Lima y Tacna para el caso peruano, y de La Paz y Santa Cruz de la Sierra para el caso de Bolivia. Adicionalmente mantuvimos varias conversaciones con otros líderes evangélicos en estas mismas ciudades. Por último, ejecutamos observaciones sistemáticas de diversos cultos realizados en templos evangélicos en las ciudades de origen, en donde asisten los creyentes indígenas. De igual modo participamos en observaciones de cultos de dos iglesias en Iquique y dos en Arica, en donde asiste una importante población migrante.

Frente a lo señalado anteriormente presentamos el concepto de postpentecostalismo ${ }^{1}$. Con la propuesta de este concepto tenemos una doble finalidad: contribuir al análisis y debate de procesos locales, la problematización y realización de comparaciones teóricas y conceptuales en el área investigada, tanto de los fenómenos religiosos en general como del pentecostalismo en particular ${ }^{2}$. De igual modo describir, en primera instancia, la emergencia y contingencia de una crisis generalizada vivida por el pentecostalismo actual. Se trata de una nueva forma de entender y practicar la religión en el pentecostalismo. Esta sigue teniendo centralidad de la figura del Espíritu Santo en el nivel discursivo, pero en la práctica el pentecostalismo ha perdido su espontaneidad inicial y su carácter extático, generando una rutinización del carisma caracterizada por el afianzamiento y adaptación social (Weber 1997: 202). Y, por otro lado, su mundanización se ha constituido en otra forma de inconciencia, indiferencia y desafección social. En síntesis, el postpentecostalismo es una nostalgia por la dimensión dorada de la comunidad pentecostal y la esperanza por un pentecostalismo reflexivo, consciente y responsable socialmente.

Es válido preguntarse ¿por qué es importante conocer o asignarle importancia a la visión de los migrantes evangélicos? Por dos motivos. En primer lugar el rol del pentecostalismo y su relación con la migración quedó estancada en el debate rural-urbano 
aymara (Pérez, 1975; González, Y.1980; 1981; González, S. 1990; Tudela, 1993). No solo hay un atasco en las investigaciones de pentecostalismo y migración, sino que también estas investigaciones abordaron la relación del pentecostalismo con la migración de manera muy tangencial. Desde este horizonte se preocuparon por lo que el pentecostalismo ofrecía a los migrantes, pero no hubo una preocupación por lo que los migrantes aportaban al pentecostalismo. Hoy, ante un escenario de globalización, no se trata solo de cambiar el enfoque o el énfasis de la investigación, sino de situarlo en el contexto geográfico, social y cultural del fenómeno migratorio que generalmente es un fenómeno relacional, complejo y múltiple.

En segundo lugar, debido al crecimiento económico y la expansión del mercado laboral, Chile se ha convertido en los últimos años en uno de los principales polos de atracción de migrantes sudamericanos, especialmente de peruanos y bolivianos, muchos de ellos indígenas (aymaras y quechuas). Si bien este fenómeno afecta a Chile en general, su presencia es especialmente significativa en la zona de norte del país. Esta zona colinda con los vecinos países de Perú y Bolivia, y presenta una historia de larga tradición en términos de flujos migratorios e intercambios económicos, políticos y socioculturales, tanto en Arica (Díaz, et al. 2004: Díaz, 2006), cono en Iquique (Tapia, 2012, González, 2006). Esta presencia se ha visto acrecentada durante la última década y ha comenzado a afectar a la sociedad local. Pero las dimensiones religiosas, especialmente pentecostales e indígenas, quedan subsumidas en la categoría de migración.

\section{La fragilidad comunitaria}

Hasta la década de 1980 las iglesias pentecostales funcionaban como comunidades familiares, donde primaba el principio de lo tuyo es mío y lo mío es tuyo. No se daban diezmos, sino ofrendas, porque era mucho más dinero que los diezmos, ya que prácticamente nadie tenía un trabajo estable. Las primicias como pescados, mariscos, gallinas, huevos, carne de cerdo, eran compartidas y repartidas entre los más pobres de la congregación. Las ofrendas eran pan con chicharrones (grasa de cerdo), kuchenes, cazuelas o pescados fritos. En ese entonces la casa del pastor era una extensión del templo, los creyentes llegaban a casa de sus hermanos de Iglesia sin previo aviso. Muchos hijos de pastores abandonaron las iglesias de sus padres por la falta de privacidad, el trato duro hacia los niños, la desatención del pastor de sus hijos o bien por la pobreza y miseria de la casa pastoral. En el imaginario pentecostal los hijos de pastores lindan entre dos representaciones: "los hijos de pastores lo peor" (Garma, 2005) o "hijos de pastor víctimas. En esta concepción positiva de la comunidad pentecostal, los pastores sacaban a los descarriados de los bares, las vigilias terminaban en comidas y los ayunos en comidas en la iglesia. La iglesia se volvía más importante que la familia.

Eran tiempos en que las canciones de campañas evangelistas eran los hits en las iglesias y se reproducían innumerables veces en los casetes. Cuando los hombres se descarriaban, la responsabilidad no era de él sino del diablo. Cada uno disfrutaba del gozo, la paz y la seguridad que brindaba la comunidad. No había miedo porque los pecadores y los "malos" estaban en el mundo. Y para evitar eso había que alejarse del mundo: evitar que el mundo entrara en la casa por la "caja del diablo" (televisión), no ir a la Universidad, ni aceptar algún trabajo que pudiese alejar al creyente de la iglesia. El tema preferido de las predicaciones era el arrebatamiento (premilenio) y ni siquiera se podía ir al cine o ir a ver un partido de fútbol, porque en cualquier momento el arrebatamiento podría ocurrir. Como recordara Bauman, "la compañía y la sociedad son malas, pero nunca la comunidad. Tenemos el sentimiento que la comunidad es siempre buena" (Bauman, 2009: 5). Según nuestras observaciones y lo observado por los migrantes, este comunitarismo ya no se vive en el pentecostalismo en las ciudades de Arica e Iquique, pero sí aún es vivido en las iglesias observadas y consultadas de Perú y Bolivia.

Esta práctica comunitaria se continúa practicando en sus iglesias de origen. No se trata solo de una nostalgia, pues está presente aún en las iglesias visitadas, incluso las neopentecostales. Por ejemplo, ante la muerte de un fiel de la iglesia, durante nuestro trabajo de campo asistimos a dos funerales en la ciudad de Iquique. Antes, recuerda un informante clave de la iglesia Asambleas de Dios, "toda la iglesia se hacía parte en los velatorios, funerales y acompañamiento a los familiares directos. En cambio hoy solo asisten los líderes de la iglesia a los ritos velatorios y funerarios y en el acompañamiento solo lo hace el pastor" (mujer anciana). Por otro lado una mujer adulta mayor de La Paz, Bolivia, destaca: "cuando yo tuve un accidente de tránsito y estuve postrada en cama. La iglesia, también Asambleas de Dios 
de la Paz, enviaba varias veces a la semana a dos mujeres para que vaya para hacer aseo, cocinar y me atienda a mí y mis hijos que estudiaban, Además, como no podía trabajar, el pastor me dió un pequeño sueldo durante un año, hasta que me recuperé y pude trabajar". Información que fue confirmada por el pastor de la iglesia en cuestión de La Paz, cuando lo entrevistamos y además él agregó que le daba un sueldo mensual mínimo solidario a 10 mujeres ancianas, previo informe de una asistente social. Eso en Chile no se hace, porque se concibe que el evangelio social es una invención socialista. El pastor antes mencionado es de Las Asambleas de Dios y lo hace por su influencia aymara. Él dice que en su iglesia hay extremo de profesionales como médicos y profesores, que abren espacios solidarios de atención, para las personas muy pobres que asisten a su iglesia.

La teología pentecostal puede ser entendida como una teología de la pobreza. Se basa en una concepción bíblica y de Dios muy antigua, que está presente en los distintos grupos que se han constituido al margen de los grupos religiosos dominantes. Donde más se hizo manifiesto esta teología fue en el pentecostalismo definido por distintos sociólogos, como "la religión de los pobres" (D’Epinay, 1968), "la religión de los desheredados" (Browning, 1930), "la religión de los desechados" (Hurtado, 1942), etc. Es la religión donde los pobres de la ciudad, los campesinos, los indígenas, los inmigrantes y las mujeres encontraban o encuentran un lugar (Willems, 1968; Foerster, 1995). El problema no está en ser una iglesia de los pobres, sino en impedir que los pobres dejen de ser pobres o legitimar la pobreza como virtud divina, igual que cuando el catolicismo decía que los "pobres eran los preferidos de Dios". De esta manera la teología de la pobreza es una teología de clase social: el evangelio es para los pobres, y Dios les sigue amando, en tanto permanezcan pobres. No obstante, desde el momento en que comiencen a experimentar alguna movilidad social, comenzarán a perderse y alejarse de Dios, o Dios se irá alejando de ellos. Por ello, como destacó Míguez, "las estrategias pentecostales de superación de la pobreza presentan dos limitaciones: i) son más útiles para los momentos más agudos de la crisis o personas en marginalidad extrema; ii) en el caso de las relaciones familiares es posible la restitución de las relaciones tradicionales, pero no favorece a la mujer en cuanto a los roles de género (Míguez, 2001: 84, 85).
Desde la teología de la pobreza se desconfía de la movilidad social, del conocimiento y la inteligencia. Se pensaba que cuanto más ignorante y analfabeta era la persona, más fiel era a Dios. Entonces un creyente perfecto era pobre, analfabeto e ignorante, por creer que "la letra mata" la fe y su relación con Dios. De este modo, se transforma en una teología que concibe a Dios con lo tremendo y terrible, un misterio que es a la vez terrorífico y fascinante (Otto, 1982). Se piensa que Dios siempre da pobreza a los suyos y miseria para que le sirvan y le teman. Predican que Dios es dueño de la riqueza y la inteligencia, pero piensan que la riqueza y la inteligencia son aliados diabólicos, porque corrompen el alma. Para el caso de Chile, esto estaba muy en concordancia con el duro trato al cuerpo: ayunos, vigilias, oraciones en el templo. En estas reuniones los niños y los ancianos son incorporadas. Esto aún se practica en las iglesias de origen de los migrantes. Por ejemplo en un culto pentecostal quechua observado en Santa Cruz de la Sierra el pastor dijo: "el próximo domingo habrá Santa Cena, para preparar nuestros espíritus tendremos tres días de ayuno: comenzaremos el jueves". En contraste, en los cultos pentecostales chilenos el ayuno es prácticamente inexistente o bien solo lo practica el liderazgo. Por ello el pentecostalismo chileno no es concebido como pentecostal por los migrantes entrevistados; porque ha abandonado el sacrificio.

La teología de la pobreza es más una protesta que una propuesta. Como destaca André Corten: "la aspiración a la pobreza, antes que ser un principio de identidad, es un principio de oposición" (Corten, 1996:33). Aunque no se trata de protestantismo, sino de un principio pentecostante (Mansilla, 2016), es decir, una protesta religiosa de los pobres blandiendo el poder del Espíritu Santo, resaltando la vida como sufrimiento, sacrificio y negación de las pasiones. Este discurso le trajo tanto rédito al pentecostalismo que redujo la vida religiosa al espiritualismo, es decir, a la idea de que lo único real es lo espiritual, conllevando un rechazo a todo lo material y lo corporal. Si bien para los pentecostales el cuerpo es un templo de Dios, al mismo tiempo es el centro del mal. Se trata de un doble pesimismo antropológico: suspicacia somática e intelectofobia. Este es uno de los motivos del desencanto de la segunda y tercera generación de pentecostales que nos habla Garma (2005). Es el tipo de pentecostalismo que vivieron o aún siguen viviendo los evangélicos migrantes 
que viven en Chile y de cuando en cuando vuelven a sus ciudades de origen.

La teología de la pobreza fue significativa y satisfactoria en tiempos en que dos tercios de la población chilena era pobre. Esta pobreza se materializaba en las abyectas viviendas ${ }^{3}$ : epicentro de miserias, enfermedades, hambre y muerte. Un país en constante urbanización pero sin industrialización, con altos índices de desempleos, subempleos, alta natalidad. En este contexto social, el discurso de concebir a los pobres como virtuosos ayudó al pentecostalismo a identificarse como una religión de clase: la religión de los pobres. Pese a la educación gratuita, tampoco la escolaridad era funcional a los pobres, por el contrario, esta va contra sus proyectos porque un niño o una niña que estudiara era una "mano de obra menos en casa". Solo importaba aprender a leer y a escribir. Asistir a la Universidad, tan lejos y tan distante de la realidad de los pobres, no era una opción. Por ello el discurso del pentecostalismo de que "la letra mata el espíritu" tuvo tanto éxito. Por otro lado un pastor analfabeto no importaba mucho, porque lo relevante era que fuera afectivo, dedicado a atender a las personas, que brindara auxilio a los desamparados, que hospedara a los sin hogar, que recogiera la gente de las calles y que orara por los enfermos. Para ello lo que importa es el afecto y no la letra: el pastor era un padre, no un profesor. Para la realidad aymara, hoy por hoy "el pastor es como un líder de la comunidad pentecostal, adquieren funciones parecidas a las del Yatiri o el Jilakata, fundamentales para el acompañamiento de la comunidad" (Tancara, 2009: 24).

No obstante, al llegar la crisis económica de la década de 1980, las mujeres y madres debieron dejar sus hogares para salir a trabajar. Fueron ellas las que impulsaron a sus hijos a estudiar, a que cumplieran la gran meta de terminar la Enseñanza Media. Por tanto esa generación de pentecostales con Enseñanza Media, incluso con profesiones técnicas, educaron a sus hijos para la Universidad en la década de 1990 o del 2000. Porque en los 80 y hasta mediados de los 90 la Universidad y la casa propia eran un sueño. La idea asociada a la mujer como dueña de casa era un eufemismo de pobreza. La imagen de mujer, madre y trabajadora generó tal impacto en la nueva generación de mujeres jóvenes universitarias, que hoy existe una tendencia creciente que ya no quieren ir a la iglesia, no quieren casarse y no quieren tener hijos. Se oponen a la homogeneización de los estereotipos sociales asignado a las mujeres. En primer lugar porque la madre que salió a trabajar aumentó significativamente su horario laboral: trabajaba en el hogar, trabajaba fuera del hogar y trabajaba en la iglesia. La vida de la mujer de la década de 1980 adquirió un carácter heroico, que las hijas no quisieron heredar. Además la nueva generación de mujeres aprendió a ser consciente de opresión y explotación laboral femenina, pero también a criticar y reflexionar respecto de la sublimación religiosa de la desigualdad de género, como aquella que debían "callar en la congregación" porque solo el hombre tenía el derecho de la palabra en el púlpito. De igual modo debía guardar silencio en el hogar porque "el hombre era la cabeza del hogar" y también "debía guardar silencio en el trabajo" porque los reclamos de derechos laborales era cuestión política, que los pentecostales debían evitar, por el contrario, el pentecostal estaba llamado a honrar al patrón, honrar al padre, honrar al esposo y honrar a las autoridades políticas (también mayoritariamente hombres). Se trataba de evocar un sistema patriarcal, y hoy por hoy las mujeres antes señaladas rechazan esta ideología.

Por otro lado, el neopentecostalismo actual es consumidor de la teología de la prosperidad. Al respecto una entrevistada que asiste a una iglesia neopentecostal en Iquique nos dice: "siento que en la iglesia también me tratan como nana (trabajadora doméstica) y no como hermana. Siempre me asignan a la cocina, nunca me siento a la mesa a comer con los otros hermanos... las personas que tienen más son mejor tratadas". Un entrevistado peruano señala: "encuentro que la iglesia chilena es muy mundana, celebran el " 18 " al interior de las iglesias, hacen ramadas, celebran la Navidad con árboles de Pascua y la gente no asiste a las reuniones de oraciones". Se trata de una percepción de los migrantes entrevistados, quienes niegan o rechazan que esto sea pentecostalismo. De igual modo la nueva generación de pentecostales critica a este pentecostalismo porque lo consideran anacrónico y las redes sociales son los púlpitos para predicar este desencanto.

La teología de la prosperidad nace en Estados Unidos en 1950 y se expande en la década de 1980, especialmente en América Latina: Brasil, Argentina, Colombia y Guatemala han sido los países donde más ha tenido éxito. Si la teología de la pobreza defiende que un pastor es aquel que vive entre la pobreza y la miseria, la teología de la prosperidad defiende que los pastores y predicadores deben 
vivir entre el bienestar material y la riqueza, ya no se trata de ser como antes "siervos de Dios", sino "empresarios de Dios", centrado en la idea de que Dios llamó a los creyentes para "ser reyes y sacerdotes". Así, la teología de la prosperidad es una teología del poder y del dominio, por lo que no es parte de denominaciones sino de los llamados ministerios, es decir, líderes religiosos independientes. Si la teología de la pobreza es característica de los pentecostales, la de la prosperidad es del neopentecostalismo. Las predicaciones son desplazadas por las charlas motivacionales, centradas en el dinero. Como destaca Edir Macedo, símbolo de la teología de la prosperidad, "la ofrenda es la sangre de la Iglesia".

Otro de los problemas de la teología de la prosperidad es que demoniza la pobreza, la considera como falta de fe, pues los hijos de Dios deben ser bendecidos materialmente. De igual forma el "no dar" es considerado como falta de fe. Se trata, entonces, de una religiosidad epicuriana, donde el sentido de la vida cristiana es la felicidad y el placer (eudemonismo y hedonismo). Así, el dolor, la enfermedad, la angustia, la soledad, el divorcio, etc., son obra del diablo o la falta de fe. Aquí las prácticas religiosas dejan de ser comunitarias y se constituyen en individuales, aunque no desaparecen las comunidades. Pero este problema se observa mayormente con las corrientes neopentecostales chilenas. En cambio en una iglesia neopentecostal observada en La Paz, Bolivia; en una reunión de oración había unas 150 personas orando y un centenar de ellas eran mujeres indígenas, algunas de ellas con sus bebés tras la espalda. Lo llamativo de estas mujeres era que oraban en aymara, danzaban, cantaban o estaban extasiadas en el suelo con toda libertad.

La Teología de la pobreza y la Teología de la prosperidad son los extremos de un continuo: una es espiritualista y la otra materialista. La primera se centra en el cielo y la otra en el materialismo terrenal. Ambas son paradigmas religiosos que tienen sus universidades, colegios, seminarios, libros e intelectuales orgánicos que defienden y sacralizan el paradigma. Los creyentes de ambas teologías se acusan mutuamente. Ninguno se escucha, sino que se acusan de ser doctrinas y mensajeros del diablo y sacan a relucir un sinnúmero de textos bíblicos para defender su posición y acusar a la otra de herejía. Ambas teologías usan al Espíritu Santo como instrumento: la primera como recurso de la espiritualización y la segunda como recurso del materialismo. En la primera Jesús es solo salvador del alma y en la otra Jesús es solo salvador de la pobreza; en una Jesús es sanador del cuerpo y en la otra es sanador del alma. En los templos neopentecostales los indígenas son subsumidos en lo nacional y en lo evangélico, pero paradojalmente son en estos templos donde el indígena migrante encuentra el espacio y el tiempo de liberación extática, donde puede orar en su lengua, pese a que se dan condiciones comunitarias precarias.

Ambas son teologías conservadoras en lo social, lo político y lo cultural. En lo social ninguna considera que ayudar al prójimo sea una prioridad. La primera piensa que solo hay que preocuparse por el alma de la persona. Hay que ayudarle en la medida que se convierta. Mi prójimo es mi próximo. Toda ayuda social es innecesaria. La segunda considera que lo importante no es tanto su alma, sino su ofrenda: "Mi prójimo es el que ofrenda". A la persona hay que ayudarla a llegar a la iglesia como sea para que ofrende. Ambas consideran que toda ayuda social es socialista, comunista y que el fin de la iglesia no es la ayuda social, sino solo la evangelización y la construcción de templos. La predicación no está llamada a cambiar la sociedad, únicamente al individuo. Ambas teologías son individualistas. En lo político son teologías conservadoras, muchas veces confundidas con grupos religiosos de derecha. No porque sean políticos, sino porque se autodefinen apolíticos. Ambas culpan al individuo de su situación económica: piensan que alguien que no tiene trabajo, o es pobre, es por flojo. Algunos culpan al Estado por la ayuda social, porque propicia la flojera. Pero la gran mayoría culpa al diablo, como el gran artífice de los males políticos. Ambas teologías critican la política pero no a los políticos. Critican a los trabajadores pero no a los empresarios. Critican las libertades sexuales y morales pero no critican la inmoralidad política, empresarial o policiaca. El pentecostalismo chileno históricamente se ha autoidentficado como apolítica (d'Epinay, 1968), pese a su abierto apoyo a Pinochet en diciembre de 1974. Pese estas contradicciones la desafección política es observable. Sin embargo el pentecostalismo peruano y boliviano es distinto, incluso las mismas denominaciones como Las Asambleas de Dios o Evangélica Pentecostal, sus creyentes participan en política. Un pastor de la iglesia Asambleas de Dios de La Paz, que es aymara, dice: "los evangélicos aymaras bolivianos no podemos de dejar de ser 
políticos, para nosotros las política no es diabólica, sino que es una responsabilidad comunitaria: participar es un deber individual".

Ambas teologías resultan impotentes para cambiar una sociedad o una ciudad que contribuya al interés público. Su único interés de cambiar la sociedad es hacerla evangélica. No son teologías que incentiven la responsabilidad social, sino el individualismo. Una mujer aymara boliviana de La Paz nos decía "para mí a Evo Morales lo puso Dios, él no es político para mí, sino un hermano. Cuando él llegó a mi comunidad yo me acerqué y le di un abrazo y le dije Dios te bendiga hermano...¿Alguien de ustedes [nos preguntan a nosotros] ha recibido un abrazo de su presidente?". En cambio en los templos visitados en nuestro trabajo de campo, tanto de Iquique como Arica, se manifiesta un fatalismo político: Dios pone a las autoridades, por tanto ante este determinismo político ¿qué importancia tienen el voto individual?

Lo más sugerente es que los creyentes de ambas teologías viven para criticarse mutuamente, nunca hay autocrítica. Mientras siguen estas mentalidades, los templos se constituyen en pasillos de membresía que circulan de iglesias en iglesias. Por ello, aunque la teología de la prosperidad parezca atractiva, en tanto apela al egoísmo y al materialismo, produce creyentes materialistas y desinteresados de la sociedad. La teología de la pobreza transforma a los creyentes en conformistas y conversionistas. Ambas contribuyen al desencanto pentecostal. Pese a que el indígena, el migrante y el pobre encuentran un lugar en el pentecostalismo, se les dice que todo su pasado religioso, sus tradiciones y su patrimonio intangible son demoníacos y que debe vaciarse de él. En el neopentecostalismo lo indígena es subsumido por lo nacional: no se valora la "indianidad" sino la nacionalidad. Luego esa nacionalidad es elevada a la metanacionalidad: todos somos ciudadanos del cielo. De los pastores entrevistados solo un pastor logró insertar el discurso proindígena al mesianismo pentecostal. Él dijo que: "cuando regrese a Jesús recuperaremos nuestras lenguas y nuestras identidades indígenas, ya que Dios las creó, incluso las lenguas que se perdieron serán resucitadas, porque las hablarán los muertos resucitados: así lo dice Apocalipsis 5". Este es un discurso muy importante porque es una alta autoridad de las Asambleas de Dios de Perú, lingüista y profesor de quechua: pero es una estrella solitaria en medio de los discursos homogeneizantes.

\section{La comunidad diluida}

Chile comenzó a cambiar vertiginosamente con el retorno de la democracia. En este escenario, el gozo prometido de la religión fue reemplazado por la alegría de la democracia, y el futuro del cielo fue desplazado por el presente social. Si bien tanto la sociedad chilena como la mentalidad de los creyentes pentecostales han cambiado durante los últimos años, la institucionalidad pentecostal y su discurso parecen estar centrados únicamente en la evangelización, como lo hacía en los 80. A eso apuntan las críticas de la nueva generación de pentecostales. Continúan con prédicas que subrayan una espiritualidad abstracta, la vida ultraterrena y una exigencia exagerada en la asistencia a los cultos. No existe un mensaje de responsabilidad social, política, cultural o histórica para el creyente; y se continúa pensando a Jesús "contra la cultura". El pentecostalismo chileno pareciera no poder llegar a los sectores medios, como sí lo ha logrado en Bolivia y Perú. Este pentecostalismo se ha parapetado en cultos rutinarios y sosteniendo discursos poco representativos de los tiempos actuales, caracterizados por la incertidumbre, la precariedad, la flexibilidad laboral y el individualismo, en vista de ello no resulta atractivo para los sectores medios.

Hay un sector de pentecostales que no aceptan los cambios del Chile contemporáneo y solo ven en ellos varios obstáculos. En este contexto, muchos pentecostales (adultos y mayores) anhelan un pasado idealizado. Extrañan las extensas vigilias, los fervorosos testimonios, las semanas de oraciones. Es la nostalgia de una comunidad con una identidad común, aquella comunidad-communitas (Turner, 1988) que existió hasta los tiempos de la dictadura, cuando la religión fue una comunidad frente a los peligros sociales del régimen autoritario, por lo menos en muchas iglesias pentecostales. Esta corriente o grupo está en consonancia con los pentecostales migrantes, que extrañan esa comunidad pentecostal. Una mujer boliviana aymara entrevistada nos dice: "en las iglesias chilenas ya no se predica en la calle, ya no se ayuna, ni se ora ni mucho; menos hay bautismos del Espíritu Santo, son iglesias frías. Yo salgo a predicar sola por las ferias de la ciudad de Iquique". Pero esa comunidad se ha diluido, volviéndose flexible, abierta y precaria. Porque como han destacado los postfundacionalistas comunitarios, la comunidad no tiene esencia sino 
existencia (Nancy, 2000; Esposito, 2003) y por lo tanto es afectada por el contexto social.

En las predicaciones de las iglesias de donde vienen los migrantes indígenas aún se usan distintas fábulas para describir el carácter del hombre y la mujer actual, con el fin de vincular el hombre con el animal, en la lucha con la vida por la supervivencia. Caracterizando su egotismo y brutalidad en la escasez; la astucia y la artimaña para ganar; y la sobrevivencia del más fuerte o inteligente en la selva urbana. Por eso los caracteres del hombre y del animal se equiparan. El instinto de conservación domina sobre muchos sentimientos románticos. La fauna está muy presente en los discursos pentecostales de los migrantes entrevistados, para representar la conducta humana, condicionada al contexto geográfico. Varias mujeres indígenas entrevistadas están marcadas por la violencia física, psicológica y sexual. Una entrevistada joven nos dice: "los hombres cuando quieren ayudar a una mujer sola, lo hacen pensando en cobrar favores por sexo". Otra mujer adulta nos dice: "uno necesita de un hombre no porque una no pueda sostenerse sola, sino porque los hombres cuando te ven sola buscan aprovecharse y abusar de las mujeres solas". Pero el creyente pentecostal se representaba a sí mismo como oveja o paloma y los sujetos no pentecostales como lobos o serpientes.

En Lima o La Paz hay templos neopentecostales más grandes, amplios y exitosos que en Chile. Por ahora en Chile solo existe un solo templo neopentecostal que está en Santiago, que es propiedad de la Iglesia Universal, pero es un templo pequeño, en comparación con los movimientos neopentecostales de las capitales antes nombradas. Incluso en el neopentecostalismo, tanto de la Paz como el de Iquique, las iglesias son fuertemente integradoras del migrante. Pero en el caso de La Paz, los movimientos neopentecostales disponen obras sociales como escuelas de alfabetización, clínicas dentales, policlínicos, hogares de ancianos, de niños u hogares terapéuticos para la superación de drogodependencias. Sin embargo en Chile eso no es frecuente ni común, porque el pentecostalismo desestimó toda obra social, toda responsabilidad social, solo existen algunas pequeñas obras sociales lideradas por personas, pero no por iglesias.

Mientras los pentecostales migrantes conciben que el mal está fuera de sí mismos y de la comunidad, por tanto, se consideran a sí mismos como víctimas de un sistema social bestial, deshumanizado y deshumanizante; los pentecostales chilenos interpretan la sociedad desde un prisma urbano concibiéndola como precaria, flexible y absorbida por la incertidumbre, la soledad y la angustia. Los pentecostales ya no se autoconciben como inmunizados a estos problemas sociales. Consideran que el mal es ubicuo y ha inoculado al pentecostalismo dejando de ser la comunidad necesitada: el sujeto desencantado dice no precisar de comunidad, porque se ha vuelto abrumadora y sofocante. De ahí que, así como los creyentes católicos han usado la expresión "soy católico a mi manera" para denotar un tipo de práctica religiosa que es laxa, flexible y que está abierta a la interpretación personal del creyente, hoy la expresión se ha extendido al mundo evangélico y de manera particular al pentecostal, señalan: "soy evangélico a mi manera".

En el pentecostalismo clásico muchas de las problemáticas que padecían los creyentes eran entendidas como responsabilidades individuales. Por ejemplo, el enfriamiento de la fe o la tibieza no se debían al pastor o la iglesia, sino al mismo creyente. Quienes no estaban de acuerdo eran expulsados de las iglesias y fundaban una nueva congregación. Así, siempre estaba la probabilidad de resistirse a la rutinización del carisma. Más allá del incontable número de congregaciones que surgieron, el valor residía en poder fundar algo nuevo y distinto.

Los creyentes se han cansado o decepcionado del espiritualcentrismo pentecostal y las iglesias se constituyen en pasillos de creyentes que buscan nuevas experiencias religiosas. Una tendencia mundial que los sociólogos han asociado a la precariedad del creer y lo efímero de lo parroquial, emergiendo exploradores de experiencias espirituales. Pareciera que la globalización y la postmodernidad religiosa han generado un tecnocreyente individualista que utiliza las redes para "alimentarse" espiritualmente (Mansilla, 2007; Jaimes, 2012). En ese sentido los creyentes migrantes, pese a ser críticos de la falta de compromiso de los creyentes chilenos, practican lo mismo, porque de igual modo su parroquialismo se ha vuelto diverso y asisten a varias iglesias. Pueden ir a tres distintos templos durante la semana. Una mujer boliviana entrevistada dice: "los días domingos en la mañana voy a Bethel (Asambleas de Dios) y en la tarde voy a una iglesia pequeña que queda cerca donde vivo. En ambas iglesias tengo hermanas conocidas de mi país”. Quizás una de las razones de por qué 
los migrantes evangélicos asisten a varias iglesias es porque en sus ciudades de origen sus iglesias realizan varios cultos el día domingo. Además los templos son columnas que sostienen los puentes que los ligan con la red de migrantes.

Es posible apreciar que los valores postmodernos influyen en el creyente. Actualmente sus frustraciones, malestares y fracasos ya no los atribuye exclusivamente al diablo y los demonios, como era la norma en el pasado. Ahora critica y ataca al sistema pentecostal mismo. La crítica es desplazada de un símbolo metafísico al sistema religioso, generando un descentramiento de la responsabilidad individual. El bienestar personal y familiar se le sigue atribuyendo a Dios, y la presencia y la bendición de Dios se mide por la prosperidad y la bendición material, como ocurre en general con la sociedad chilena de mayoría católica. Antes, la bendición se medía por la cantidad de horas asistidas a la iglesia y las almas ganadas, y hoy, por las certificaciones de los hijos y los bienes adquiridos.

Uno de los grandes pilares del pentecostalismo fue su autonomía económica: siendo una religión de los pobres, logró movilizar a esta población para que donara sus diezmos y ofrendas al pastor, a los creyentes más desvalidos, y también para construir y reparar templos. Este modelo de economía religiosa sigue rindiendo frutos entre los creyentes indígenas de Perú y Bolivia, mientras que en la mayor parte de Chile se agotó. Es justamente en el mundo indígena donde opera el principio del don dentro de la economía religiosa, lo que permite desarrollar valores como la responsabilidad, la solidaridad, la generosidad, la confianza y la retribución. La prédica pentecostal le asignó un valor trascendental a estos valores comunitarios, generando una afinidad valórica. $\mathrm{Al}$ respecto, pequeño empresario peruano de origen quechua que realiza comidas en su casa para invitar migrantes peruanos y bolivianos. Además, junto con su esposa, dirigen una iglesia pequeña. Por medio de estas festividades y celebraciones generosas y solidarias produce una retribución de recursos.

Sin embargo, la teología de la prosperidad desarrollada en el seno del pentecostalismo rompe con esta afinidad. Bajo esta concepción desaparece la importancia del diezmo, pues se considera que no es suficiente. La figura de la ofrenda se vuelve más relevante. Sin embargo, esta tiene un interés material: hay que ofrendar para recibir, por lo que suele ser vista como una inversión. Pareciera entonces que muchas veces el creyente se preocupa más del tener que del ser. Además, los escogidos de Dios se conocen porque son bendecidos materialmente, y experiencias como el sufrimiento, el sacrificio y la laboriosidad, pueden ser vistas también bajo un fin económico y material. Pero también se rompe con la concepción clásica de la comunidad y se vive una comunidad flexible, diluida e instrumental.

Otro de los valores de los pentecostales, heredado de los protestantes, es la valoración al trabajo. El trabajo es concebido como un valor trascendental: Dios creó al ser humano para el trabajo libre. Mientras que las condiciones opresoras, explotadoras y humillantes del trabajo son concebidas como un acto demoníaco y diabólico. El problema de la herencia pentecostal es solo asignarle valor al "trabajo manual", pero esto resulta relevante para los migrantes indígenas, ya que ellos trabajan mayoritariamente en construcción, ferias y trabajo doméstico. Por tanto el trabajo manual es el trabajo por excelencia. El problema es que los pentecostales no son críticos ni incentivan a la protesta por las condiciones sociales y laborales opresoras, desiguales y explotadoras del trabajo que afectan, principalmente, a los migrantes. Si bien las conciben como algo diabólico, la voluntad divina es resistir, no rebelarse y por tanto se les enseñan a obedecer, acatar y guardar silencio frente a las injusticias.

Actualmente la noción de pastor y su autoridad ha cambiado considerablemente, pues ha sido desprovisto de su significado asociado a una sociedad tradicional, rural, indígena o campesina. El concepto de pastor se ha vuelto vacío y por ello algunos nuevos líderes se autodenominan apóstoles, profetas o simplemente conferencistas (título más propio de una sociedad globalizada). Tanto en el pentecostalismo chileno como en el imaginario de los migrantes, la idea de pastor está asociada a la pobreza, pues se cree que debe ser un trabajo voluntario y cualquier mejoría social que adquiera el pastor es vista como un aprovechamiento individual. Por su parte, los pastores neopentecostales hacen uso simultáneo de sus títulos profesionales y sus títulos religiosos, señalando que sus sueldos y beneficios son producto de su esfuerzo, y por tanto legítimos. Por otro lado, la autoridad del pastor ha sido socavada por una generación perspicaz y suspicaz que no tolera que la autoridad se fundamente en la afectividad o el "llamado". Esta nueva generación exige un fundamento vocacional pertinente con 
los tiempos, basado en la educación teológica, la educación universitaria (en la medida de lo posible) y una dirección eclesiástica transparente y guiada por el diálogo. Sin embargo, esto cambios son muy difíciles de lograr porque el pentecostalismo clásico se esforzó muchísimo en no ser del mundo, alejándose de él y volviéndose una religión extraña, difícil de asumir una responsabilidad social con el mundo.

\section{Reflexiones finales}

El postpentecostalismo es una etapa emergente de una crisis generalizada vivida por el pentecostalismo actual, en donde encontramos tres niveles de críticas. En primer lugar están los creyentes más "comprometidos" o "antiguos", quienes son críticos de que, pese a la centralidad de la figura del Espíritu Santo en el nivel discursivo, el pentecostalismo habría perdido su espontaneidad inicial y su carácter extático, generando una rutinización del carisma caracterizada por el afianzamiento y adaptación social (Weber 1997). Esto le habría convertido crecientemente en una religión más del mundo, pero simultáneamente alejada del mismo: no estarían en el mundo, pero tampoco en el espíritu. He ahí la centralidad del desencanto: no tienen el fuego (espíritu), ni actúan en el mundo (conciencia, compromiso, responsabilidad).

En segundo lugar están los creyentes jóvenes y jóvenes adultos, especialmente profesionales, que son críticos del pentecostalismo por su ausencia de conciencia, compromiso y responsabilidad social. Resaltan que es una religión excesivamente espiritualista y espiritualizante, que la prédica es descontextualizada, cuestionan la ausencia de formación profesional y teológica de los pastores así como un excesivo énfasis en la asistencia cúltica.

Por último, junto con esta transformación interna del propio pentecostalismo, el movimiento se ha visto afectado por ciertas dinámicas contemporáneas. En este artículo nos centramos en una de ellas: la migración transfronteriza. Así, nos pusimos como objetivo analizar la visión que poseen los creyentes migrantes indígenas evangélicos acerca del pentecostalismo chileno, explorando la relación que establecen entre esta forma de pentecostalismo y la que profesaban en sus países de origen. Frente a ello destacamos que las poblaciones migrantes indígenas conciben deontológicamente al pentecostalismo chileno como una manifestación fría, rutinaria e indiferente y que no se encuentra en sintonía con su religión de origen.

\section{Referencias Citadas}

Bauman, Z.

2003 Comunidad. En busca de seguridad en un mundo hostil. Siglo XXI, Argentina.

Browning, W. et al.

1930 The West Coast Republics of South America: Chile, Peru and Bolivia. New York: World Dominion Press.

Bourdieu, P y Wacquant, L.

2008 Una invitación a la sociología reflexiva. Argentina: Siglo XXI.

Corten, A.

1996 Os Pobres e o Espírito Santo o pentecostalismo no Brasil. Bozes, Sao Paulo.

D'Epinay, C.

1968 El Refugio de las masas: Estudio sociológico del protestantismo chileno. Santiago de Chile: Editorial del pacífico.

Díaz Araya, A.; Ruz Zagal, R.; Mondaca Rojas, C.

2004 "La administración chilena entre los aymaras: resistencia y conflicto en los Andes de Arica (1901-1926)". En revista Antropológica Número 22. Lima. Perú.

Díaz, A.

2006 Aymaras, peruanos y chilenos en los andes ariqueños: resistencia y conflicto frente a la chilenización del norte de Chile. AIBR, pp. 296-310.

Espósito, $\mathrm{R}$.

2003 Communitas. Origen y destino de la comunidad. Buenos Aires: Amorrortu.
Foerster, R.

1995 Introducción a la religiosidad mapuche. Editorial Universitaria, Santiago de Chile.

Garma, C.

2005 "Hijo de pastor, lo peor". En Más allá del espíritu. Carolina Rivera y Elizabeth Juárez, CIESAS, México, pp. 53-90.

Geertz, C.

2005 La interpretación de las culturas. España: Gedisa.

González, S.

2006 La presencia indígena en el enclave salitrero de Tarapacá: Una reflexión en torno a la fiesta de La Tirana. Chungará, Revista de Antropología Chilena, 38 (1), 35-49.

González, Y.

1980 La familia aymara: una estructura desintegrada y dominada. Cuaderno de Investigación Social 3: 34-38.

González, Y

1981 La nuclearización de la estructura familística autóctona y el proceso de dominación interna. Cuaderno de Investigación Social, 4: 24-29.

González, S.

1990 El aymara de la provincia de Iquique-Chile y la Educación Nacional. TER, Iquique.

Hurtado, A.

1945 ¿Es Chile un país católico? Santiago de Chile: Ercilla. 
Jaimes, R.

2012 El neopentecostalismo como objeto de investigación y categoría analítica. Rev. Mex. Sociol [online]. vol. 74, n. 4, pp. 649-678.

Luhmann, $\mathrm{N}$.

1996 Teoría de la sociedad y pedagogía. España: Paidós.

Mansilla, M.

2007 "El neopentecostalismo chileno". Revista Ciencias Sociales, núm. 18 (invierno): 87-111.

Mansilla, M.

2016 La Cultura del Morir. La muerte en el pentecostalismo. RIL, Santiago.

Míguez, D.

2001 La conversión religiosa como estrategia de supervivencia: Los pentecostales y el descenso social durante la "década perdida". Intersecciones antropol. n. 2, pp. 73-89.

Nancy, J.-L.

2000 La Comunidad Inoperante. Escuela de Filosofía Universidad ARCIS, www.philosophia.cl

Otto, R.

2001 Lo santo. Lo racional y lo irracional en la idea de Dios. Madrid: Alianza editorial.

Pérez, E.

1975 La sociedad andina; una sociedad en desintegración. Cuaderno de Investigación Social 1: 57-74.
Tapia, M.

2012 Frontera y migración en el Norte de Chile a partir del análisis de los censos de población. S. XIX y XXI Revista Geografía Norte Grande, 52, 177-198.

Tancara, J.J.

2009 "Tuve una importante revelación. Revelación en la experiencia evangélica andina”. En Teología Andina. El tejido diverso de la fe indígena. Josef Estermann (Coor.). Tomo II. ISEAT. La Paz, pp. 15-43.

Tudela, P.

1993 Cambios religiosos y revitalización de la comunidad entre los aymaras de Arica 1960-1990. Nütram 33: 15-48.

Turner, V.

1988 El proceso ritual. Editorial Taurus, Madrid. España.

Turner, V.

1980 La selva de los símbolos. México: Siglo XXI.

Weber, M.

1997 Economía y sociedad. Esbozo de sociología comprensiva. Editorial. F.C.E. Bogotá.

Weber, M.

1998 La ética protestante y el espíritu del Capitalismo. Ediciones Istmo. Madrid.

Willems, E.

1967 Followers of the New Faith: Culture Change and the Rise of Protestantism in Brazil and Chile. New York: University of Illinois Press.

\section{Notas}

1 Desde una postura teológica este concepto ha sido trabajado por le teólogo peruano Bernardo Campo. Al respecto se puede ver el texto: El postpentecostalismo. Renovación del Liderazgo y Hermenéutica del Espíritu. En Cyberjournal for Pentecostal-charismatic Research: http://www.pctii. org/cyberj/cyberj13/bernado.html .

2 Las investigaciones sobre el pentecostalismo no son tan relevantes en América Latina, como lo es en el mundo anglosajón, asiático y africano. Solo por nombrar que existen dos importantes revista de Ciencias Sociales especializadas en pentecostalismo. Como son: Pneuma. The Journal of the Society for Pentecostal (EE.UU.) y Studies y Reviews PentecoStudies (Inglaterra).
3 En relación con las características de las viviendas, déficit e insalubridad ver: Álvarez, Oscar (1935). "El problema de la habitación en Chile". Acción Social, 43:17-28; Arteaga, Oscar (1985). "El cité en el origen de la vivienda chilena". CA. Revista Oficial del Colegio de Arquitectos de Chile, 41:18-21; Gross, Patricio (1985). "La vivienda social hasta 1950". CA, Revista Oficial del Colegio de Arquitectos de Chile, 41:12-17; Guzmán, Luis (1990). "Políticas públicas y vivienda popular: el arrendamiento en Santiago de Chile 1906-1950". Tesis para optar al grado de Magíster en Planificación Urbana. Santiago: Pontificia Universidad Católica de Chile. 
ANDROS IMPRESORES

www.androsimpresores.cl 